\title{
EL HOMBRE COMO ESENCIA ABIERTA. UNA APROXIMACIÓN A LA TEORÍA DE LA PERSONA DE XAVIER ZUBIRI
}

\section{Man as Open Essence. An Approach to Xavier Zubiri's Theory of the Person}

\author{
Javier Eduardo Pérez Téllez \\ Universidad Tecnológica del Perú \\ Lima - Perú \\ https://orcid.org/0000-0002-9004-0211 \\ jperez_002@hotmail.com
}

\begin{abstract}
RESUMEN
El presente texto tiene por fin el acercar al lector a un aspecto delimitado del pensamiento filosófico del pensador español Xavier Zubiri (1898 1983). En particular, se busca realizar una aproximación a la antropología filosófica del referido autor a través del concepto zubiriano de realidad personal. Dado que para el pensador en cuestión ontología y antropología filosófica se encuentran mutuamente implicadas, el artículo explora sucintamente la visión de Zubiri sobre la realidad y cómo es que esta se hace presente al hombre, entendido este como animal de realidades. A partir del reconocimiento de la realidad en tanto entidad existente de suyo se posibilita el acceso al modus existendi de la persona humana y a sus caracteres específicos, a saber, esencia abierta y suidad.
\end{abstract}

\section{Palabras clave:}

Sustantividad, esencia abierta, persona, realidad.

\begin{abstract}
This article aims to provide the reader with an approach to a bounded aspect of the thought of the Spanish philosopher Xavier Zubiri (1898-1983). Particularly, it seeks to explore Zubiri's philosophical anthropology bymeans of the analysis of his concept of personal reality. Given that, for this author, ontology and philosophical anthropology are interrelated terms, the text offers a brief review of Zubiri's conception of reality, and how it makes itself present to human beings understood as animal of realities. By means of the recognition of reality as existent by itself, it is possible to gain access to the modus existendi of the human person and to its main characters: open essence and 'suidad'.
\end{abstract}

\section{Keywords:}

Sustantivity, open essence, person, reality 


\section{Hombre y realidad}

Xavier Zubiri (1898-1983), insigne pensador español, solía señalar que el hombre era un animal de realidades. La animalidad como elemento constitutivo del hombre es algo que ya señalara en su tiempo Aristóteles, pero el que sea un animal de realidades comprende un nuevo aporte al conocimiento de la realidad humana por parte este filósofo español y merece ser explicado. Como nos refiere Zubiri en su obra Estructura dinámica de la realidad (1989):

Al hacerse cargo de la realidad, en virtud de esa función, las cosas no se presentanal hombre como medio, sino como mundo. Lo cual, dicho en otros términos, significa primero que el hombre es radical y constitutivamente una esencia abierta. Abierta precisamente al carácter de realidad de las cosas. No está enclasada, pendiente de la cualidad de los estímulos, sino que está, en principio por lo menos, abierta en primera línea a su propia realidad. No da sus respuestas únicamente en virtud de la talidad de las suscitaciones, sino que da esas respuestas haciéndose cargo de la realidad, y de lo que a él realmente le va a acontecer. Estructuralmente, el hombre -digoes un animal de realidades (p. 216).

El hombre, para el filósofo de San Sebastián, no se encuentra meramente presente en la realidad, del mismo modo en que podemos decir que una mota de polvo se encuentra flotando en el espacio o que un animal cualquiera se encuentra en su hábitat, sino que su manera particular de habitar lo real implica una asunción formal y consciente de la dimensión espacio, como también puede decirse lo mismo del hombre con respecto al tiempo $\mathrm{y}$ al mundo intersubjetivo. La realidad humana se hace presente en lo real como aprehensor del mismo en cuanto real y simultáneamente aprehendiéndose a sí mismo en el proceso en tanto realidad. Ahora bien, ¿Qué es la realidad? Es claro que para poder comprender adecuadamente la antropología filosófica de Xavier Zubiri es menester comprender qué entiende nuestro autor por realidad, puesto que para él la persona humana misma se adscribe al mundo y a lo real y se encuentra en permanente apertura a aquel, de tal suerte que su constitución como realidad personal tiene como correlato su religación a lo real. Siendo así, el conocer qué entiende nuestro filósofo por realidad facilitará la comprensión de su antropología filosófica; dicho en otros términos, para conocer el quién es necesario conocer el qué, aunque el qué y el quién se refieran a distintas dimensiones de un modo de lo real eminentemente indiviso y único. Lo primero a tener en cuenta es que el filósofo donostiarra parte de la existencia de una realidad que no es creada por las operaciones del entendimiento, sino que tiene una existencia de suyo. En ¿Qué es investigar? (2005), nos señala nuestro autor que investigar implica un buscar la verdad, más la verdad no es algo que se construye a partir de elementos creados ex nihilo por el mismo intelecto humano, ni una mera percepción que solo existe en tanto percepción y, por tanto, como producto inmanente del entendimiento humano. En abierta oposición a posturas solipsistas, señala nuestro pensador que la verdad es una actualización de lo real que se hace presente al hombre a partir de una inteligencia a la vez sensitiva e intelectiva; es así que el entendimiento humano no puede ser tenido como una res cogitans o pensamiento puro que meramente concibe en abstracto la realidad del mismo modo 
como un algoritmo informático almacena y procesa información, sino que el hombre accede a la verdad como actualización de lo real mediante una razón que a una concibe y siente la realidad, siendo ambos momentos indivisibles en virtud a la estructura unitaria del modo específico de existir de la realidad humana, la misma que se hace patente a partir de una estructura que, es necesario reiterarlo, siempre reposa en unidad,por lo cual el proceso de inteligir el mundo es siempre un proceso de inteligir la realidad y, en simultáneo, sentir dicha realidad. La aprehensión del mundo es una operación que incluye tanto la intelección de lo real como el sentir lo real, en momentos que de suyo pertenecen a un mismo proceso que solo en abstracto, mas no en un sentido fáctico, se pueden separar en "sensación e intelección. Es por ello por lo que Zubiri asume que el hombre es inteligencia sentiente. Como nos dice el filósofo vasco: "¿Qué es lo que se investiga? Evidentemente investigamos la verdad, pero no una verdad de nuestras afirmaciones,sino la verdad de la realidad misma. Es la verdad por la que llamamos a lo real, ommunio verdadera" (Zubiri, 2005 , p.5). Lo real es lo que se muestra a la inteligencia sentiente del hombre como verdadero y existente desde sí mismo o de suyo, en términos de nuestro autor. El mundo se hace presente al hombre como existente desde sí con anterioridad al proceso de aprehensión por parte de la persona humana. Es así que Zubiri nos instaura en un mundo de realidades, un mundo en el que hay seres con existencia de suyo, hay realidades ajenas a mí y que limitan la expansión de mi yo; en términos estrictos, la realidad no es solo lo exterior al Yo, sino que la persona misma es realidad que se aprehende y actualiza a sî misma. La realidad humana se intepreta, por tanto, a sí misma en tanto que realidad prima fascie y es por ello que en el sentido común suele interpretarse como desvarío el negar la propia existencia, lo cual es de por sí una contradicción ontológica, pues un acto de negación consciente requiere como condición de posibilidad la existencia y la aprehensión formal de la propia realidad fundamental constitutiva.

La realidad, como tal, no es monolítica, sino que en ella se ubican distintos modus existendi. La sola contraposición del hombre frente al mundo implica de suyo una contraposición entre dos formas radical y constitutivamente opuestas entre sí, entre dos modos de realizar lo real, cada una de ellas con sus propios atributos y, por tanto, con una estructura o configuración distinta de lo real. Nos dice sobre el particular Zubiri (2005):

Cada cosa con que estamos nos impone una manera de estar en la realidad. Y esto es lo decisivo. (...) Esta cuestión de qué es ser real es, ante todo, una auténtica cuestión por sí misma. Porque las cosas no son tan sólo el riquísimo elenco de sus propiedades y de sus leyes, sino que cada cosa real y cada propiedad suya es un modo de ser real, es un modo de realidad. Las cosas no difieren tan sólo en sus propiedades, sino que pueden diferir en su propio modo de ser reales. La diferencia, por ejemplo, entre una cosa y una persona, es radicalmente una diferencia de modo de realidad. Persona es un modo propio de ser real. Es necesario conceptuar, pues, lo que es ser cosa y lo que es ser persona, es decir, hay que investigar qué es ser real (pp. 3, 7).

Lo real abarca, como ya ha sido mencionado, tanto al hombre como a 
las realidades no humanas, pero que, en tanto realidades, estas se imponen a la inteligencia sentiente $\mathrm{y}$, por tanto, el mundo conocido comprende una comunión de realidades. Aplicado esto a las realidades personales como el hombre, ello se traduciría como communio personarum.

\section{La constitución de lo real: la sustantividad}

Lo real, de acuerdo a nuestro autor, está articulado por sistemas que conforman las distintas realidades y que no se distinguen de estas. Los dichos sistemas se constituyen por elementos que aportan atributos al sistema en cuanto tal a partir de la mediación que se da en la interrelación de los distintos elementos constitutivos de dicho sistema. Es de tal interrelación que se forma una unidad armónica que es acto fundante de la esencia del sistema. Dicha esencia tiene primacía ontológica frente a los elementos que conforman el sistema y es, en términos de la ontología fundamente de la sustantividad, anterior a las notas. Para entender tal concepción de lo real, piénsese en una pintura. En una pintura encontramos distintos colores y formas. Encontramos, también, tanto una realidad conceptual inherente a la obra de arte, a la par que encontramos que los elementos conceptuales se expresan por medio de la materialidad de la misma. No comprendemos la pintura a partir de una separación de los elementos conceptuales de la obra y los elementos materiales, del mismo modo que no se comprende la obra a partir de los colores por separado de las formas que contienen los colores; comprendemos las significaciones del cuadro a partir de la totalidad de los elementos de la obra de arte. Dicha totalidad nos brinda una ley constituyente de la obra a partir de la cual los distintos elementos del cuadro se vuelven inteligibles; en otros términos, la comprensión del todo es condición de posibilidad para la comprensión de las partes. Del mismo modo, la sustantividad es un sistema en el cual se entienden los momentos constitutivos del mismo a partir de la esencia del ser sustantivo, por cuanto los elementos constitutivos o notas, en el lenguaje de Zubiri, no determinan la sustantividad, sino que esta posee una coherencia fundante en la cual co-participan las notas, de cuya unidad emerge la esencia de la sustantividad; de la sustantividad podemos decir, por tanto, que es más que el mero agregado de sus notas. En palabras de Zubiri:

[L]a articulación de las notas de una realidad es estructura cuando por ella posee propiedades sistemáticas, algo irreductible a la mera copulación externa de elementos. Habituados a la idea de unidad sustancial, esta idea de la unidad de la sustantividad puede parecer más laxa, una unidad de rango inferior. Pero no es así; la verdadera y radical unidad de lo real es la unidad de sustantividad. (...) La máxima unidad metafísica es la unidad estructural de la sustantividad (Zubiri, citado por Hernanz, s/f).

Como ya se ha referido antes, estos sistemas de notas o sustantividades no son monolíticos, es decir, varían de acuerdo a su propio modus existendi. Como se ha visto previamente, no es lo mismo existir como persona que existir como cosa y, si bien ambas son realidades, su constitución ontológica es, naturalmente, distinta y, por tanto, se hace necesario comprender lo propio del ser personal para dar cuenta de este particular modusexistendi. 


\section{El ser humano como esencia abierta}

Habíase mencionado que la realidad humana no solo se encuentra en la realidad de forma lejana, a modo de espectadora del devenir, sino que toma parte de lo real y entra en comunión con él en la medida que el hombre es, también, realidad, más una realidad con un modo propio de ser real, a saber, como realidad personal. Pues bien, llegados a este punto es menester presentar y explicar el concepto de sustantividad, que ya había sido mencionado, pero no plenamente explicitado en lo específicamente relacionado al hombre. Veamos que nos dice el filósofo vasco a este respecto en su obra Sobre el hombre (1998):

La realidad humana es un constructo psico-orgánico organizado, solidario y corpóreo, que en su misma organización, solidaridad y corporeidad es un constructo abierto. El hombre se enfrenta con las cosas como realidades, esto es, es animal de realidades porque es estructuralmente una sustantividad abierta (p.65).

En primer lugar, el ser humano no es un mero agregado de partes coordinadas entre sí, sino que es una entidad con dimensiones varias, como la psicológica y la orgánica, que se encuentran mutuamente imbricadas en la estructura de la realidad personal, de tal manera que no hay un divorcio entre estas distintas categorías, sino que estas forman un todo indiviso. El ser humano no es una concatenación de sistemas divisos en áreas concatenadas por mecanismos reguladores y coordinadores, sino que actúa de tal modo que la existencia forma un sistema de propiedades en las cuales sus notas constitutivas están todas mutuamente implicadas entre sí de tal manera que lo "psíquico" no es separable de lo "físico" ni este de lo "espiritual" y, propiamente, este carácter de significación común que tienen las distintas dimensiones de la realidad personal y que traspasan todo el drama de la existencia humana se debe a que el hombre es un tipo especial de lo que Zubiri llama "sustantividad". Demos la palabra al filósofo de las provincias vascongadas en su obra Sobre la esencia (1963):

[L]a sustantividad no es nada distinto de lo que hemos llamado 'sistema', sino que consiste en el sistema en cuanto tal; no es nada oculto tras él. (...) un sistema es una unidad primaria e intrínseca, en la cual las diversas notas no son sino momentos parciales, posicionalmente interdependientes, en los que se actualiza el sistema como unidad (pp.151-152)

Las sustantividades son así sistemas de propiedades o notas, en el lenguaje de nuestro filósofo, que se co-determinan mutuamente y que constituyen el sistema como un todo, sin que la cosa o sistema pueda separarse de estas; son así, elementos constituyentes del sistema y la realidad estaría conformada por el conjunto de sistemas dados en la formalidad del entendimiento humano por la inteligencia sentiente. Estos sistemas se caracterizan por ser totalidades propias, es decir, son esquemas de realidad en que encontramos un orden coherente a partir de una ley de constitución que emerge a partir de la codeterminación de elementos o notas constitutivas del sistema o sustantividad. La sustantividad sería así una totalidad independiente, es decir, una unidad inteligible que no es parte en sí de otra entidad, sino que 
tiene cierta autonomía constitutiva dada a partir de una regulación o ley común a todas las notas o elementos constitutivos del sistema, las mismas que se encuentran clausuradas, es decir, que no se encuentra abierto a recibir más notas constitucionales, pues de ser así el sistema no sería inteligible al estar en permanente estado de indefinición. Las notas se ordenan entre sí de forma ordena y cíclica, en un circuito cerrado. Cabe mencionar que hay tipos de notas y que son, justamente, las constitucionales las que hacen posible la integración común. Ahora, todo lo anterior no implica que las notas no puedan existir fuera del sistema; pueden, pero de dispersarse las notas constitucionales el sistema dejaría de ser. La razón de lo anterior estriba en que el sistema como totalidad no se diferencia del conjunto interrelacionado de las notas. A diferencia del accidente en la teoría de la sustancia, las notas son necesarias para la constitución del sistema sustantivo y, sin ellas, este simplemente dejaría de ser, pues estas se codeterminan y una alteración de esta codeterminación implica una desestructuración de la cosa en cuanto tal, del mismo modo que una alteración por radiación en un ente vivo sobre su ADN puede hacer surgir patologías que sean causantes de la disgregación de la unidad orgánica del organismo y, por tanto, de su muerte. Una vez que se constituye el sistema puede hablarse en propiedad de una esencia, es decir, de un sistema de notas con una identidad definida. Retomemos ahora al hombre. El hombre es una sustantividad, sí, pero como se ha mencionado antes, por ejemplo, en ¿Quées investigar? El hombre posee una modalidad existencial que le es enteramente ajena a la cosa o al animal no humano. Es por ello que no es posible predicar del hombre que es una sustantividad sin más, aunque como entidad de la realidad es un sistema de notas. Dada la estructura de la sustantividad, las notas que conforman lo humano no pueden conceptualizarse como cajones de un mueble cuyos contenidos se encuentran completamente aislados entre sí.

Es por ello que referíamos las distintas dimensiones del ser humano se encuentran en un proceso de integración profunda que hacen del hombre una totalidad $\mathrm{O}$, como dirá Zubiri después, un absoluto relativo. Esto no implica, naturalmente, que la sustantividad humana no tenga "momentos" o secciones constituyentes, más debemos entender estos momentos dentro del esquema de lo que otro filósofo, Maurice Merleau-Ponty, llamaba "forma", es decir, una entidad en la que el todo es ontológicamente anterior a las partes. Es por eso por lo que Zubiri no separa la inteligencia y la sensibilidad, sino que nos refiere que la inteligencia es sentiente. Como nos dice nuestro autor (1998):

En realidad 'física' sólo hay un sistema total. En él, todas y cada una de las notas psíquicas son 'de' las notas orgánicas, y todas y cada una de las notas orgánicas son 'de' las notas psíquicas. El hombre, pues, no 'tiene' organismo 'y' psique como si uno de los términos fuera añadido al otro, sino que el hombre 'es' psico-orgánico, es una sustantividad psico-orgánica. Es una estricta y rigurosa unidad estructural de sustantividad, es la unidad intrínseca, formal y estructural de organismo y psique. Este organismo es formal y constitutivamente 'organismode' esta psique; y esta psique es formal y constitutivamente 'psique-de' este organismo. La psique es desde sí misma orgánica, y el organismo es desde sí mismo psíquico (p.59). 
Dicho esto, debemos entender por tanto que todo momento de la existencia humana es vital para su desenvolvimiento $y$, por tanto, que debemos considerar al sustrato biológico y animal del humano como medio de realización de la persona y como portador de las notas constitutivas que posibilitan nuestro carácter personal. En términos científicos, la estructura genética es condición de posibilidad para el desarrollo de las estructuras somáticas, pero esta estructura genética permite no solo desarrollar tales estructuras somáticas, sino también las funciones cognitivas superiores. De hecho, las primeras células humanas en aparecer durante la generación del nuevo individuo humano, las células totipotenciales, contienen en sí la capacidad de convertirse tanto en células propias de tejido óseo, como en células hepáticas, como en células nerviosas que serán vitales para el desarrollo cognitivo y los procesos mentales como atención, memoria, etc. Ahora, conviene reiterar que el hombre, si bien es sustantividad, no es como las demás sustantividades. Esto se debe a que en la estructura de lo humano su sustantividad es inconclusa, es decir, el hombre no es como el animal, que opera por meros estímulos, pues en el hombre estos estímulos pueden provocar una respuesta automatizada somáticamente, pero el estímulo se presente como una realidad de la que hacerse cargo y que tienen como origen una realidad existente de suyo. Este momento de reflexividad da al hombre una feliz plasticidad de la que el animal carece; por el contrario, el hombre es esencia abierta: su suidad o capacidad de auto posesión le faculta para incorporar nuevas notas a su sistema de tal manera que su esencia no permanece inalterada, sino que se va constituyendo mientras va modulando su personalidad por medio del ejercicio de la libertad en la elección de sus actos. Es así como puede decidir acceder a sus instintos, más puede, por libre y espontánea decisión, oponerse al instinto en aras a conseguir un objetivo no marcado por su animalidad, sino por su libre arbitrio en consonancia con su propia forma de realidad, es decir, como realidad personal. Así, puede negarse a alimentarse como forma de protesta ante una situación que se vive como injusta y oprobiosa, por ejemplo. El estímulo no esclaviza al hombre al despliegue de un automatismo biológico, sino que lo interpela como persona y exige de él una respuesta personal, la misma que será tal sea que decida asumir el llamado del instinto como renuncia al mismo, puesto que en todas estas acciones está presente el asentimiento consiente de la voluntad tras la aprehensión reflexiva de la manifestación de lo real como instancia interpelante. Es por ello que la esencia del hombre está abierta, pues no está supeditada en modo absoluto a los imperativos de la estimulidad, sino que puede tomar decisiones $y$, en tal medida, irse actualizando a sí mismo como persona, como se verá más adelante. Es así que solo las personas son sustantividades y realidades inacabadas, inconclusas. Naturalmente, nada de esto sería posible sin la nota de la inteligencia. Ahora, está apertura a la realidad y la capacidad de dar cuenta como realidad es la que permite el dar cuenta de sí mismo en cada acto y, como tal, ser dueño de estos y de sí mismo, de poseerse a sí mismo y a su naturaleza. Esto es lo que Zubiri llama la "suidad".

\section{La persona humana}

Hasta el momento, hemos realizado una pequeña aproximación a cómo Zubiri comprendela realidad, cómo es que esta se encuentra constituida, cómo es aprehendida por el hombre y cuál es 
la relación entre realidad y aprehensión formal, conocimiento y verdad. Asimismo, se ha descrito al hombre como animal de realidades y cómo está estructurado en sus notas constitutivas. Ahora, resta explicar al hombre en tanto realidad personal, es decir, describir aquella estructura característica de la existencia humana que le permite ostentar el nombre de persona. Según el filósofo de País Vasco (1984)

Todas las demás realidades tienen de suyo las propiedades que tienen, pero su realidad no es formal y explícitamente suya. En cambio, el hombre es formalmente suyo, es suidad. La suidad no es un acto ni una nota o sistema de notas, sino que es la forma de la realidad humana en cuanto realidad (p. 48).

Analicemos lo que nos refiere en la última cita el pensador vasco: tenemos el conjunto de realidades que constituye el mundo y encontramos que estas realidades se caracterizan por poseer un momento constitutivo de suyo, es decir, que poseen propiedades inherentes a estas que son previas al acto de la aprehensión y que, por tanto, trascienden la constitución de la subjetividad en un plano trascendente con respecto a la realidad humana. El caso es que entre las realidades a aprehender encontramos al mismo ser humano, a la comunidad humana y a nosotros mismos como parte de esa comunidad. El proceso de aprehensión intelectiva nos actualiza como aprehensores, de tal manera que con la aprehensión se revela al aprehensor a ojos de sí mismo, es decir, hay un develamiento de la realidad humana desde sí como realidad personal de suyo, puesto que al aprehenderme me descubro a mí mismo como una realidad que no es mera realidad de suyo, sino que la posee de forma no solo moral sino formal y constitutiva. En otros términos, el hombre no solo es naturaleza, sino que la posee como propiedad suya y, por tanto, tiene como imperativo el hacerse cargo de esa realidad que es la suya propia. Esto es lo que Zubiri llama "suidad", es decir, el hombre no es solo que sea realidad, (que lo es), sino que se tiene a sí mismo como realidad encomendada. De tal manera, el hombre se descubre como un ser que tiene propiedades de suyo, como las demás realidades, pero que, además de poseer propiedades de suyo, se posee a sí mismo como suidad y es la suidad, como nos revela Zubiri, la forma en que habita el mundo la realidad humana, es su modus existendi. Es así que dentro del sistema de notas que conforma la esencia del hombre, una de estas notas es la capacidad de diferencia inherente y reflexiva con respecto a sí mismo y capacidad, por tanto, de autoposeerse y tener carácter formal de suidad. Diríase, por tanto, que la suidad es una propiedad constitutiva desde la genética misma de la persona humana. Es, por tanto, la suidad el elemento constitutivo de la personeidad, lo que le hace ser, en palabras de Zubiri, "reduplicativamente suyo". La suidad se erige, así como el ser de la persona comoestructura específica de existencia y en virtud del cual todos los hombres son personas encuanto tienen de suyo esta propiedad fundante. Dicho esto, es ya posible avanzar sobre las relaciones que establece Zubiri entre personeidad y personalidad, que, más allá del aparente juego de palabras, no son, naturalmente, lo mismo. Personeidad, término creado por el propio Zubiri al no encontrar una palabra exacta que exprese la categoría concebida por él, es la estructura del propio existir en merced a la cual la realidad que posee este modo de existir posee como notas suyas la autoposesión y la inteligencia. La estructura específica del ser que tiene suidad e inteligencia como notas suyas constitutivas es la 
personeidad, que, como estructura suya y modus existendi, ni se gana ni se pierde, sino que es presente al hombre desde su generación hasta su muerte. Sin este ser persona en específico no es posible el desarrollo de la inteligencia, ni la socialización ni la libertad, pues estos elementos tienen como condición de posibilidad la personeidad como configuración existencial o modo de existir específico de un ser de la realidad. Toca ahora ver lo que es personalidad. Zubiri lo entiende como la forma específica en que se va a desarrollar la personeidad en un individuo concreto en la medida que este va configurándose a sí mismo como una forma específica de persona en base a sus acciones libres, espontaneas y voluntarias. Es por ello que el hombre es sustantividad abierta, pues puede modular su esencia de acuerdo a su obrar. La acción humana se torna, en este punto, fundamental, pues es ella la que permite al hombre configurar su identidad personal de forma libre y espontánea, aunque con las limitaciones que impone la realidad social, histórica, etc. El hombre no es capaz de realizar todo lo que su voluntad exige, más el caso es que puede elegir entre determinadas posibilidades y, al elegir, se elige a sí mismo como persona, y esto tanto en un sentido constructivo y benéfico como en un sentido negativo. Por decisión libre el hombre puede cultivar hábitos que modelen su carácter al punto de convertir en una persona virtuosa. Asimismo, de forma libre el ser humano puede elegir aquello que es pernicioso, como en el caso del criminal, quien elige un derrotero de vida que, finalmente, se vuelva contra sí mismo. El punto es que con nuestras acciones vamos modulando y configurando nuestra personalidad y, por tanto, elegir acciones es elegir el tipo de persona que se desea ser. Mientras más nos adentremos en las acciones más nos habituaremos al estilo de vida elegido y al tipo de persona elegido, para bien o para mal, generando así la posesión de un tipo específico de persona. Naturalmente, esto no implica que el régimen de vida adoptado $y$, por tanto, la personalidad no sea modificable. Como bien señala Zubiri, la personalidad se puede "hacer" y "deshacer" (sin negar por ello el rol del carácter y, en general, de los genes, las experiencias infantiles, etc.), más estas cosas, como propias de la persona, son un legado que la persona posee en suidad y que, por tanto, debe asumir y modular de forma inteligente), es decir, es posible, con mucha fuerza de voluntad, el re-modular la personalidad para cambiar de derrotero vital. Es así que, como puede verse, de la estructura de lo real hemos saltado a la estructura del hombre y la persona y de esta a los actos como configuradores y moduladores de la existencia humana. Con ello, el pensamiento de Zubiri concatena lógicamente las variables realidad sin más y realidad personal, esto es, ontología y antropología filosófica. Tal es justamente una fortaleza del pensamiento zubiriano: brinda un esquema metafísico que permite conceptualizar la realidad de forma coherente de modo diáfano y con la suficiente claridad conceptual como para explicitar como en dicho esquema de realidad se inserta la persona humana.

\section{REFERENCIAS BIBLIOGRÁFICAS}

Hernanz,J. (s/f). La sustantividad zubiriana como superación de la obsolescencia teórica de la metafísica sustancialista. Instituto de Filosofía UV. Recuperado de: https://cdigital.uv.mx/bitstream/ handle/123456789/38651/ Ergo 15 pag $139-189$.pdf? Sequence $=2$ EisAllowed $=y$ 
Zubiri,X. (1989). Estructura dinámica de la realidad. Madrid, España: Alianza Editorial.Zubiri, X. (1984). El hombre y Dios. Alianza Editorial.

Zubiri, X. (2005). ¿Qué es investigar? The Xavier Zubiri Review, Vol. 7. Recuperado de: http://biblio3.url. edu.gt/Libros/investigar.pdf
Zubiri, X. (1998). Sobre el hombre. Alianza Editorial.

Zubiri, X. (1963). Sobre la esencia. Madrid, España: Sociedad de estudios ypublicaciones.

Fecha de recepción: 24/09/2021 Fecha de aceptación: 04/10/2021 